\title{
Detection of Theileria Equi Antibodies in Grazing Horses from The Western Border Area of Xinjiang, China
}

\author{
Ruiqi Song, Huercha, Xinli Fan, Min Li, Xuejie Zhai, Mengyuan Zhang, Jingjing Song, Yang Zhang, \\ Yongchang Li, Wei Zhang, Bayin Chahan* and Qingyong Guo* \\ Department of animal parasitlogical, College of Laboratory Animal Medicine, China \\ *Corresponding author: Bayin Chahan, Department of animal parasitlogical, College of Laboratory Animal Medicine, Xinjiang \\ Agricultural University, Urumqi, Xinjiang 830011, China \\ Qingyong Guo, Department of animal parasitlogical, College of Laboratory Animal Medicine, Xinjiang Agricultural University, \\ Urumqi, Xinjiang 830011, China
}

\begin{tabular}{|c|}
\hline ARTICLE INFO \\
\hline Received: 慧 November 29, 2019 \\
\hline Published: 㗀 December 06, 2019 \\
\hline
\end{tabular}

Citation: Ruiqi Song, Huercha, Xinli Fan, Min Li, Xuejie Zhai, Mengyuan Zhang, Jingjing Song, Yang Zhang, Yongchang Li, Wei Zhang, Bayin Chahan, Qingyong Guo. Detection of Theileria Equi Antibodies in Grazing Horses from The Western Border Area of Xinjiang, China. Biomed J Sci \& Tech Res 23(4)-2019. BJSTR. MS.ID.003939.

\begin{abstract}
To research the epidemiological situation of Theileria equi in the horse herds in the west of Xinjiang Province, 317 serum samples collected from 6 counties and districts tested for T. equi through recombination EMA1ELISA. As the result, we found that 85 of 317 serum samples (26.8\%) were positive for T. equi infection. The results showed that the chosen counties have a varying degree infection. To our knowledge, this is the first time that we detected T. equi infection using the molecular techniques from the west of the Xinjiang Uygur Autonomous Region.
\end{abstract}

Keywords: Theileria equi; EMA-1 of Xinjiang stain; Horse; Indirect ELISA; Xinjiang province

\section{Short Communication}

Theileria equi is one of the most important tick-borne hemoprotozoan diseases and infect horses, mules, donkeys, and zebras [1-3], which includes acute, subacute and chronic, nevertheless, chronic infection is not obvious [4]. The symptoms of clinical disease are fever, anemia, icterus, and hemoglobinuria [5] and in some cases, death [6]. Piroplasmosis occurs in most countries worldwide and infection is maintained within equine populations as long as competent vectors are present. The parasite and their natural tick vectors are endemic to most countries with tropical and subtropical climates where it causes significant economic loss to the horse industry [7], According to data from the Food and Agriculture Organization of the United Nations, there were about 112 million horses in the world in 2013, which about $90 \%$ of the equine species were found in endemic areas of Piroplasmosis [8]. In recent years, many surveillance studies of equine piroplasmosis have been reported in many countries all over the world, such as
Korea, Mongolia, Venezuelan, Tunisia, Sudan, Italy, Hungary, Saudi Arabia, Mexico and Texas of U.S.A. [9] International movement of horses into disease free-areas is allowed only if they have been tested negative for piroplasmosis through serological testing [10]. Therefore, for maintaining a healthy international horse industry market, it is very important that the parasites to prevent and control.

Although the CFT was previously the official regulatory test for establishing piroplasmosis status before travel to a non-endemic country, the CFT is not considered the diagnostic test of choice for chronic infection [7]. Indirect immunofluorescent antibody tests (IFAT) demonstrates high specificity but lacks sensitivity. In recent years, several ELISA detection methods established by recombinant antigen have been proved to be very effective in the diagnosis of chronic T. equi infection [11]. Xinjiang province, as the endemic area of melioidosis, has the highest infection rate (45\%), 
which restricts the healthy development of the horse industry in Xinjiang [12]. The purpose of this experiment is to use the established recombine EMA1ELISA to monitor the prevalence of $\mathrm{T}$. equi in the western border area of Xinjiang, and to provide the basis for comprehensive prevention and control.

\section{Materials and Methods}

We collected 317 blood samples from horses in Xinjiang prefecture from 2016 to 2017, locations of the horses from Chapchal, Hongnahai, Stud Farm, Military Horse Farm, Kalasu and Akesu county, which close to Kazakhstan and Kyrgyzstan (Figure $1)$. Use the serological method for the detection of recombine EMA1ELISA (rEMA1-ELISA) is established by our laboratory.

\section{Results and Analysis}

85 positive samples $(26.8 \%)$ were detected from 317 horse samples by rEMA1-ELISA (Figure 2). In this study we chose the above six sampling areas. ELISA test indicated that all of six counties existed the T. equi infection, the highest prevalence was recorded in Kalasu(E) as $67.9 \%$. the lowest prevalence was recorded in Akesu county(F) as $9.1 \%$. There were statistically significant differences observed between Tekes and Chapchal. In Chapchal (A), the average value of OD450 was the highest, indicating that the whole IgG antibody level of T. equi was the highest; in Hongnahai(B), the average value of standard deviation(SD) was the highest, which has great difference in the whole IgG antibody level.

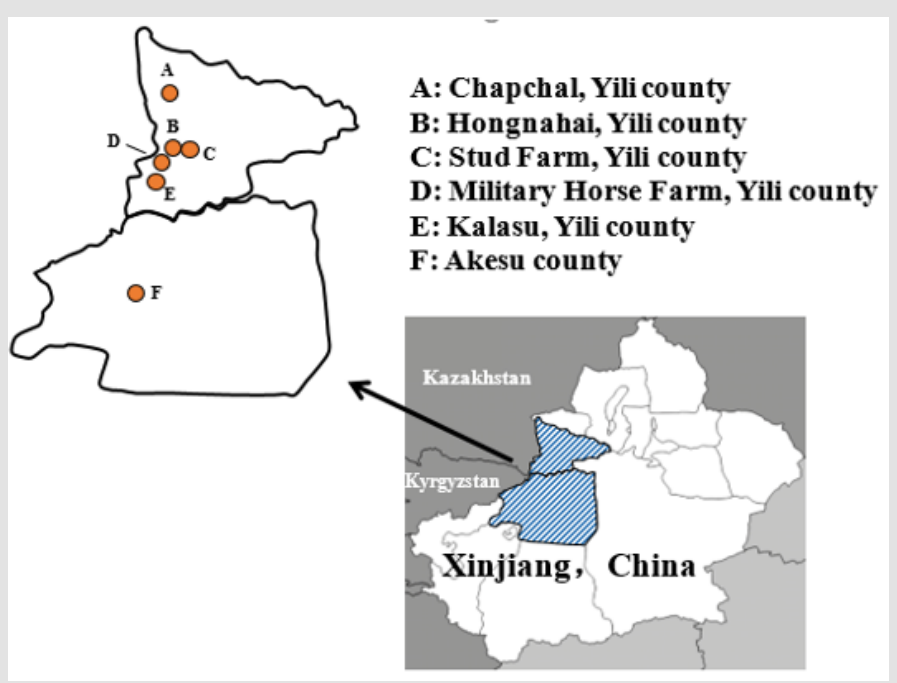

Figure 1: The collected places of sample. the west of Xinjiang, bordering Kazakhstan and Kyrgyzstan.

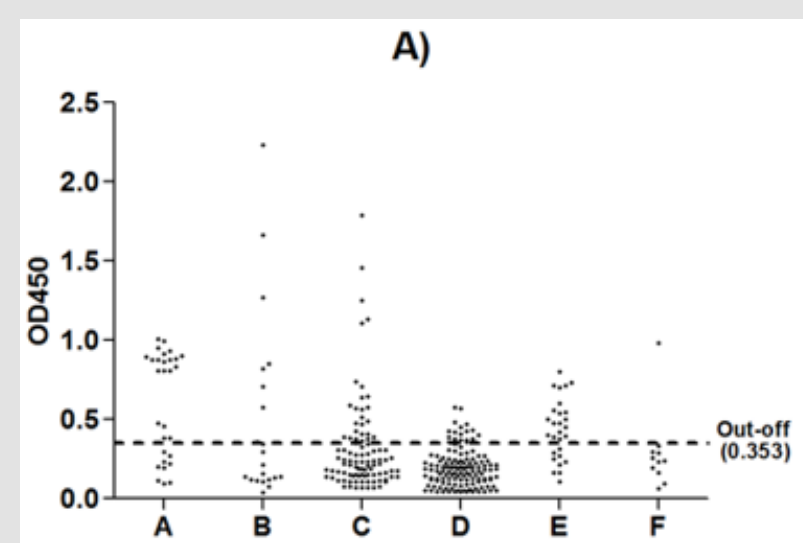

B)

\begin{tabular}{|c|c|c|c|c|c|}
\hline Region & $\mathbf{N}$ & \% & Mean & SD & SE Mean \\
\hline A & 29 & $48.3(14 / 29)$ & 0.608 & 0.331 & 0.061 \\
\hline B & 21 & $33.3(7 / 21)$ & 0.499 & 0.587 & 0.128 \\
\hline C & 96 & $27.1(26 / 96)$ & 0.317 & 0.293 & 0.030 \\
\hline D & 132 & $13.6(18 / 132)$ & 0.195 & 0.118 & 0.010 \\
\hline E & 28 & $67.9(19 / 28)$ & 0.439 & 0.190 & 0.036 \\
\hline F & 11 & $9.1(1 / 11)$ & 0.285 & 0.246 & 0.074 \\
\hline
\end{tabular}

Figure 1: Theileria equi determination using rEMA1-ELISA in Xinjiang. A) Scatter plot: Detection of Theileria equi antibodies in equine sera. The samples with a value over Out-off (0.353), located above the line represent positive values for infection with Theileria equi; B) Table: In 317 horses, the positive rate of the various regions. 


\section{Discussion}

The parasite showed that the high incidence seasons of $\mathrm{T}$. equi were spring and autumn in China. However, the average high prevalence period of the disease in Xinjiang is relatively late for climatic factors. The disease is transmitted by Ixodid tick species and has a high mortality rate if it is not diagnosed and treated in a timely manner. There are 3 generas and 17 species of ticks that can be spread to T. equi in the country, Xinjiang's tick species are more than a third of the nation ss population. There are reports that Dermacentor nuttalli, Dermacentor silvarum and Rhipicephalus haemaphysaloides have been identified as either natural or experimental vectors of T. equi [13].

Xinjiang is one of the five major pastoral areas in China. The total area of pasture is the third largest in the country, where to be next only to Inner Mongolia Tibet. A large number of ticks are bred in the rich grassland vegetation. The main form of breeding is grazing in Xinjiang, horses are more favorable to be attacked and bitten by the ticks carrying pathogens and the frequent activity of ticks, resulting in a serious epidemic of piroplasmosis, which has crippled economic growth in Xinjiang. In April 2015, the T. equi infection state in 40 Akhal-teke horses to import from Kazakhstan in Khorgos's Bureau Isolation Center of Entry-exit Inspection and Quarantine were determined by Vmrd's cELISA Kit, the results show that 6 positive samples(15.0\%) were detected from the 40 horse serum samples.

Xinjiang province western, with Kazakhstan, Kyrgyzstan, Tadzhikistan, Afghanistan and Pakistan 5 area borders, thereinto Chapchal, Hongnahai, Stud Farm, Military Horse Farm and Kalasu directly bordering Kazakhstan, and these areas also had a high infection rate. It is very likely that this phenomenon is caused by the transmission between regions during the active period of ticks, which needs further study and determination. In Xinjiang, the two seasons of spring and autumn are the active period of ticks, which is also the peak period of occurrence of the parasite each year. With the continuous occurrence and prevalence of the disease, the mortality rate, the number of miscarriages and chronic case (recessive carrying parasite horses) increased annually [14-16]. these have caused certain losses and huge potential dangers to the horse industry. Thus, in order to maintain the healthy development of horse industry in Xinjiang and improve the living standard of herdsmen in frontier areas, it is very important to monitor the IgG antibody level of piroplasmosis in prevention and control.

\section{References}

1. Mehlhorn H, Schein E (1998) Redescription of Babesia equi Laveran, 1901 as Theileria equi Mehlhorn, Schein. Parasitol Res 84(6): 467-475.

2. Kappmeyer LS, Thiagarajan M, Herndon DR (2012) Comparative genomicanalysis and phylogenetic position of Theileria equi. BMC Genomics 13: 603.

3. Bruning A, P Phipps, E Posnett, Canning EU (1997) Monoclonal antibodies against Babesia caballi and Babesia equi and their application in serodiagnosis. Vet Parasitol 68(1-2): 11-26.

4. Ming W, Wei G, Ikuo I (2014) Epidemiological Investigation of Equine Piroplasmosis in China by Enzyme-Linked Immunosorbent Assays. J Vet Med Sci 76(4): 549-552.

5. García Bocanegra I, Arenas Montes A, Hernández E (2013) Seroprevalence and risk factors associated with Babesia caballi, and Theileria equi, infection in equids. Vet Journal 195(2): 172-178.

6. Seo MG, Yuna SH, Choi SK (2011) Seroprevalence of equine piroplasms in the Republic of Korea. Vet Parasitol 179(1-3): 224-226.

7. Wise LN, Kappmeyer LS, Mealey RH (2013) Review of Equine Piroplasmosis. J Vet Intern Med 27(6): 1334-1346.

8. Bhoora R, Buss P, Guthrie AJ (2010) Genetic diversity of piroplasms in Plains zebra (Equus quagga burchellii) and Cape mountain zebra (Equus zebra zebra) in South Africa. Vet Parasitol 174(1-2): 145-149.

9. Wang M (2014) Epidemiological investigation of Equine piroplasmosis in China by enzyme-linked immunosorbent assays. J Vet Med Sci 76(4): 549-52.

10. Baldani CD, Hilario E, Nakaghi ACH (2011) Production of recombinant EMA-1 protein and its application for the diagnosis of Theileria equi using an enzyme immuno assay in horses from São Paulo State Brazil. Revista Brasileira De Parasitologia Vet 20(1): 54-60.

11. Jaffer $O$ (2010) A comparative study of serological tests and PCR for the diagnosis of Equine piroplasmosis. Parasitology Research 106(3): 709713 .

12. Bayinchahan (2015) Infection status of Equine piroplasmosis and its prevention and control in the state of Xinjiang. Chinese Association of Animal Science and Veterinary Medicine(CAAV), p. 4.

13. Shen J, Huang B (2004) A list of parasites for livestock and poultry in China. China Agricultural Science and Technology Press Beijing, China.

14. Li J, Wang ZB, Zhang Y, Bayinchahan (2014) Establishment of real-time fluorescence PCR methods for diagnosing Therlieria equi and molecular biology epidemiological studies of Ili horse. Progress in Veterinary Medicine 34(2): 124-126.

15. Ogunremi O, Georgiadis MP, Halbert G (2007) Validation of the indirect fluorescent antibody and the complement fixation tests for the diagnosis of Theileria equi. Vet Parasitol 148(2): 102-108.

16. Bhoora R, Quan M, Paul T (2010) Sequence heterogeneity in the equi merozoite antigen gene (EMA-1) of Theileria equi and development of an EMA-1-specific TaqMan MGBTM assay for the detection of T equi. Vet Parasitol 172(1-2): 33-45. 


\section{ISSN: 2574-1241}

DOI: 10.26717/BJSTR.2019.23.003939

Bayin Chahan, Qingyong Guo. Biomed J Sci \& Tech Res

(C) This work is licensed under Creative

Submission Link: https://biomedres.us/submit-manuscript.php

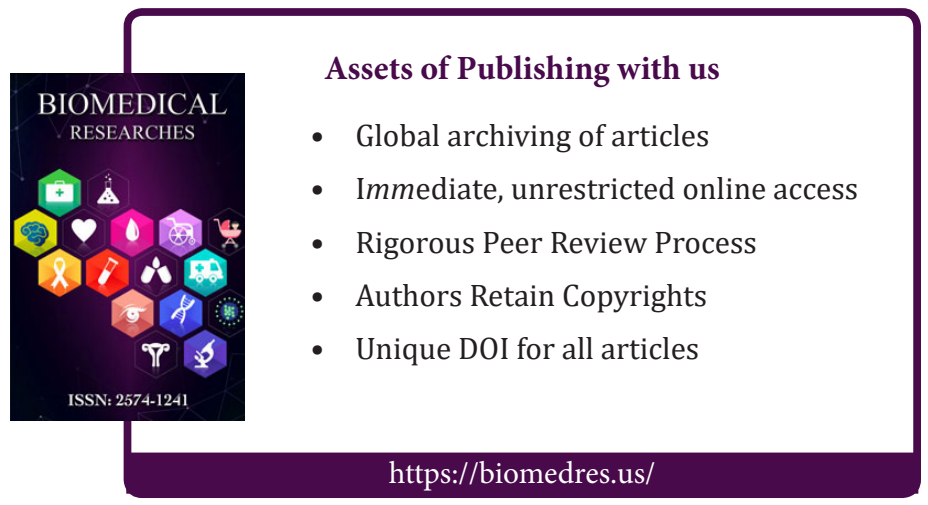

